\title{
Perencanaan Persediaan Bahan Baku dengan Penerapan Konsep Decoupling Point untuk Mereduksi Lead Time
}

\section{Cathlen Rezeky Putri*}

Prodi Teknik Industri, Fakultas Teknik, Universitas Islam Bandung, Indonesia.

*crezekyputri@gmail.com

Abstract. CV. X is a textile company that produces 20 types of fabrics. In its production activities, $\mathrm{CV}$. X experienced problems. The problem is that there is a delay in sending products to consumers or production targets that are not achieved due to delays in raw materials caused by poor production planning. The impact of these problems is that the company gets a penalty from the consumer for not being able to keep the agreement that has been made. Efforts that can be made to overcome these problems are by implementing a decoupling point and planning material requirements for supplies that are used as decoupling points. The results obtained from data processing and is the determination of the decoupling point in the sewing process. With the determination of the decoupling point, the leadtime value on CV. X was reduced from 6 days to 2 days. After determining the inventory, the next step is to propose production planning by forecasting demand, aggregate planning, then disaggregation to determine the Master Production Schedule (JPI), testing the feasibility of JPI using $\mathrm{RCCP}$, followed by planning material requirements using material requirements planning (MRP) to produce a proposed plan. ordering supplies that are used as decoupling points (grey sewing cloth) for 1 month.

Keywords: Decoupling Point, Lead Time, Material Requirements Planning.

Abstrak. CV. X merupakan salah satu perusahaan tekstil yang menghasilkan 20 jenis kain. Dalam kegiatan produksinya, CV. X mengalami permasalahan. Permasahalan tersebut yaitu adanya keterlambatan pengirimin produk kepada konsumen atau target produksi yang tidak tercapai dikarenakan keterlambatan bahan baku yang disebabkan perencanaan produksi yang kurang baik. Dampak dari permasalahan tersebut adalah perusahaan mendapatkan penalti dari konsumen karena tidak dapat menepati kesepakatan yang telah dibuat. Upaya yang dapat dilakukan untuk mengatasi permasalahan tersebut yaitu dengan menerapkan decoupling point dan melakukan perencanaan kebutuhan material pada persediaan yang dijadikan decoupling point. Hasil yang didapat dari pengolahan data dan adalah penetapan decoupling point pada proses sewing. Dengan adanya penetapan decoupling point nilai leadtime pada CV. X berkurang yang awalnya 6 hari menjadi 2 hari. Setelah ditetapkan persediaan selanjutnya yaitu mengusulkan perencanaan produksi dengan melakukan peramalan permintaan, perencanaan agregat, lalu disgagregasi untuk menentukan Jadwal Produksi Induk (JPI), menguji kelayakan JPI menggunakan RCCP, dilanjutkan dengan melakukan perencanaan kebutuhan material menggunakan Material Requirement Planning (MRP) untuk menghasilkan usulan rencana pemesanan persediaan yang dijadikan decoupling point (kain grey sewing) selama 1 bulan.

Kata Kunci: Decoupling Point, Lead Time, Perencanaan Kebutuhan Material 


\section{A. Pendahuluan}

CV. X merupakan perusahaan manufaktur yang bergerak pada bidang tekstil. CV. X melayani konsumen akhir (Business to Costumer) dan beberapa perusahaan garmen (Business to Business). Oleh karena itu, strategi merespon pasar yang diterapkan oleh CV. X yaitu Make to Stock (MTS) dan Make to Order (MTO). Strategi MTS diterapkan untuk memenuhi permintaan produk pada pasar retail. Sedangkan strategi MTO diterapkan untuk merespon permintaan beberapa perusahaan garmen. Adapun jenis kain yang merupakan produk akhir CV. X adalah kain Ceruti Celup, Mosscrape Celup, Amunzent Celup, Diamond Celup, Hicont Celup, Chiffon Fine Celup, Woll Peach Celup, Wolly Crepe Celup, Ballotely Celup, Saten Celup, Ceruti Printing, Mosscrape Printing, Amunzent Printing, Diamond Printing, Hicont Printing, Chiffon Fine Printing, Woll Peach Printing, Wolly Crepe Printing, Ballotely Printing, dan Saten Printing.

Permasalahan yang terjadi pada CV. X adalah ketidaktersediaan bahan baku utama (kain grey) saat dibutuhkan. Ketidaktersediaan bahan baku disebabkan oleh keterlambatan kedatangan bahan baku. Keterlambatan kedatangan bahan baku terjadi karena perusahaan belum melakukan perencanaan produksi dengan tepat untuk memenuhi customer lead time. Berdasarkan data keterlambatan kedatangan bahan baku pada tahun 2019, dapat diketahui bahwa perusahaan mengalami keterlambatan kedatangan bahan baku sebanyak 34 kali dari 49 kali pemesanan. Keterlambatan kedatangan bahan baku tersebut berdampak kepada keterlambatan penyelesaian produk yang mengakibatkan customer lead time tidak terpenuhi. Selain itu, keterlambatan ini juga berpengaruh terhadap kepercayaan konsumen kepada perusahaan, karena perusahaan tidak dapat menepati kesepatan awal.

Berdasarkan latar belakang yang telah diuraikan, maka dapat ditentukan tujuan dari penelitian ini yaitu:

1. Menentukan decoupling point untuk memperpendek leadtime.

2. Membuat perencanaan kebutuhan material yang dibutuhkan untuk memenuhi decoupling point.

Penentuan persediaan dapat dilakukan menggunakan decoupling point [1] dan [2]. Selain itu perbaikan perencanaan produksi dilakukan dari peramalan permintaan hingga RCCP [3].

\section{B. Metodologi Penelitian}

Decoupling point dapat membedakan kegiatan produksi berdasarkan pesanan konsumen dan peramalan permintaan, serta memberikan informasi aliran material. Selain itu, Olhager (2010) menyatakan bahwa titik aliran material berhubungan dengan kegiatan yang ada pada CODP. Kegiatan CODP terbagi menjadi dua yaitu bagian hulu dan bagian hilir. Bagian hulu CODP berfokus pada efisiensi, dan proses produksi didominasi oleh peramalan permintaan (forecast driven). Sementara itu, fokus utama pada bagian hilir CODP adalah fleksibilitas dan lead time dari konsumen, hal ini dikarenakan aliran material pada proses produksi didorong oleh pesanan konsumen (customer order-driven) [4] dan [5].

Langkah awal yang dilakukan untuk memperpendek lead time adalah dengan menetapkan decoupling point. Penetapan decoupling point dilakukan dengan menentukan terlebih dahulu bahan baku atau komponen mana yang dapat dijadikan persediaan oleh perusahaan sehingga komponen ini dapat dibuat sebelum pesanan datang ke perusahaan. Penetapan decoupling point dilakukan agar dapat memperpendek jarak antara order dengan delivery atau customer lead time.

Setelah dilakukan penetapan decoupling point selanjutnya yaitu melakukan perncanaan produksi. Perencanaan produksi diawali dengan melakukan perhitungan peramalan permintaan. Perhitungan peramalan ini dilakukan untuk memperkirakan jumlah permintaan periode berikutnya [6]. Metode perhitungan peramalan yang digunakan yaitu time series. Tahapan ini dimulai dengan menentukan jenis pola data yang sesuai dengan data permintaan kemudian dilakukan perhitungan peralaman menggunakan software WIN QSB sesuai dengan jenis pola data yang terpilih. Setelah itu dilakukan uji error untuk membadingkan metode mana yang terbaik, lalu metode yang memiliki nilai error terkecil itulah metode yang terpilih untuk hasil 
peramalan yang selanjutnya dilakukan uji validasi agar hasil peramalan dapat diterapkan [7].

Pembuatan JPI ini digunakan untuk membagi target produksi menjadi target produksi per item produk dalam bentuk JPI. Jadwal produksi induk (JPI) adalah rencana produksi yang terdiri atas jumlah produk akhir yang harus diproduksi dan kapan diproduksi. Jadwal Produksi Induk adalah hasil dari disagregrasi dan implementasi perencanaan produksi (agregate). Metode yang digunakan yaitu metode disagregasi Bitran and Hax [8].

RCPP atau perencanaan kebutuhan kapasitas kasar merupakan proses validasi JPI terhadap kapasitas tersedia [9]. RCCP ini dilakukan dengan menghitung kebutuhan kapasitas kasar yang dimiliki perusahaan untuk memproduksi produk yang nantinya berguna untuk mengambil tindakan perbaikan apabila ditemukan ketidaksesuaian antara JPI dengan kapasitas yang tersedia [9].

Material Requirements Planning (MRP) adalah suatu pendekatan dalam melakukan perencanaan dan pengendalian material yang berbasis komputer dengan cara yang terkoordinasi[10]. Perencanaan kebutuhan material ini dibutuhkan untuk mengetahui kuantitas dan waktu yang diperlukan untuk melakukan persediaan yang dijadikan decoupling point.

\section{Hasil Penelitian dan Pembahasan}

\section{Penetapan Decoupling Point}

Penetapan decoupling point digambarkan melalui bill of material. Penenetuan decoupling point dilakukan untuk menentukan titik persediaan utama dimana pengiriman ke konsumen dilakukan tetapi jumlah persediaan harus cukup untuk memenuhi permintaan konsumen pada periode tertentu. Gambar 1 dan Gambar 2 menunjukan persediaan yang dapat dijadikan decoupling point.

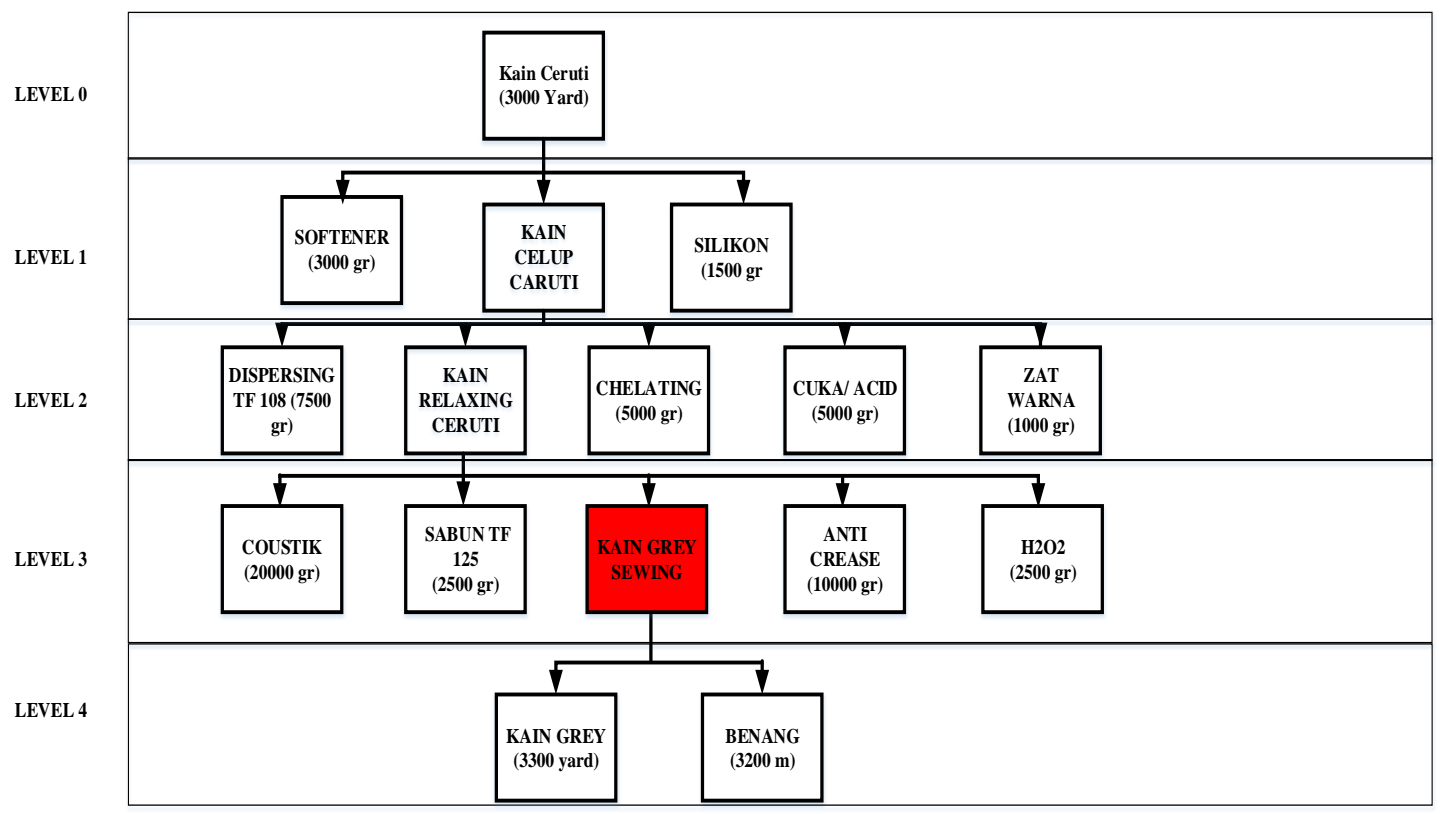

Gambar 1. Gambaran penentuan decoupling point untuk kain celup 


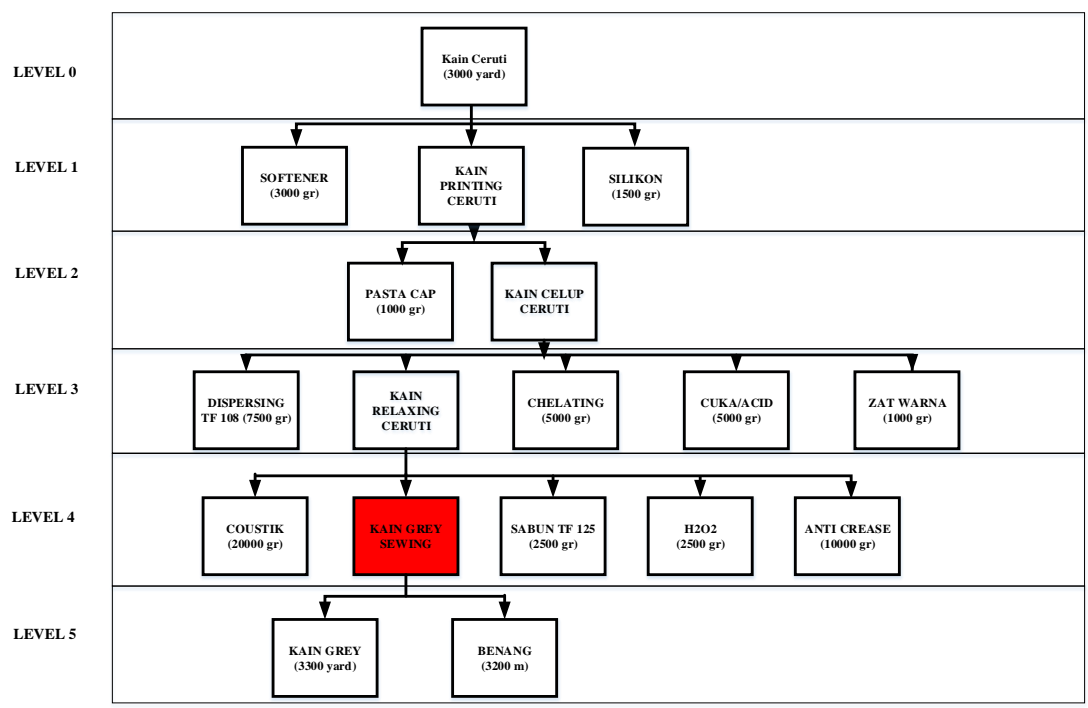

Gambar 2. Gambaran penentuan decoupling point untuk kain printing

Decoupling point dapat dilakukan pada proses sewing. Proses sewing ini yaitu proses penyambungan kain grey, jadi kain sewing ini dapat dijadikan persediaan sebelum adanya permintaan dari konsumen.

Perbandingan Lead Time Sebelum dan Setelah Penetapan Decoupling Point

Lead time yaitu waktu yang diperlukan oleh perusahaan dari pemesanan bahan baku hingga produk akhir dikirimkan ke konsumen. Lead time untuk setiap proses produksinya didapat dari nilai waktu proses terbesar pada produk yang dihasilkan. Tabel 1 merupakan perbandingan lead time sebelum dan setelah dilakukan decoupling point.

Tabel 1. Perbandingan Lead Time

\begin{tabular}{|c|c|c|c|}
\hline \multirow[t]{2}{*}{ Departemen Kerja } & \multirow[t]{2}{*}{ Nama Stasiun Kerja } & \multicolumn{2}{|c|}{ Lead Time } \\
\hline & & $\begin{array}{c}\text { hari/ batch } \\
\text { (sebelum DP) }\end{array}$ & $\begin{array}{l}\text { hari/batch } \\
\text { (setelah DP) }\end{array}$ \\
\hline \multicolumn{2}{|c|}{ Pemesanan Bahan Baku } & 3 & Sudah Tersedia \\
\hline \multirow{4}{*}{$\begin{array}{c}\text { Departemen Kerja } \\
\text { Persiapan } \\
\text { Penyempurnaan }\end{array}$} & Pile Up Kain & 0,011 & Sudah Tersedia \\
\hline & Kodefikasi Kain & 0,015 & Sudah Tersedia \\
\hline & Sewing & 0,017 & Sudah Tersedia \\
\hline & $\begin{array}{l}\text { Relaxing dan } \\
\text { Scouring }\end{array}$ & 0,022 & 0,022 \\
\hline \multirow[t]{2}{*}{$\begin{array}{c}\text { Departemen Kerja } \\
\text { Dyeing }\end{array}$} & Dyeing & 0,111 & 0,111 \\
\hline & Scutcher & 0,022 & 0,022 \\
\hline \multirow{3}{*}{$\begin{array}{c}\text { Departemen Kerja } \\
\text { Printing }\end{array}$} & Printing & 0,051 & 0,051 \\
\hline & Fiksasi / Steaming & 0,105 & 0,105 \\
\hline & $\begin{array}{l}\text { Washing / Pencucian } \\
\text { kain }\end{array}$ & 0,052 & 0,052 \\
\hline \multirow{2}{*}{$\begin{array}{l}\text { Departemen Kerja } \\
\text { Finishing }\end{array}$} & Stenter & 0,044 & 0,044 \\
\hline & $\begin{array}{c}\text { Pemotongan Pinggir } \\
\text { Kain }\end{array}$ & 0,032 & 0,032 \\
\hline \multirow{3}{*}{$\begin{array}{c}\text { Departemen Kerja } \\
\text { Packaging }\end{array}$} & Final Inspeksi & 0,148 & 0,148 \\
\hline & Rolling dob fold & 0,222 & 0,222 \\
\hline & Packing Kain & 0,185 & 0,185 \\
\hline \multirow{2}{*}{\multicolumn{2}{|c|}{ Mengirim Produk kepada konsumen }} & 1 & 1 \\
\hline & & 5,039 & 1,995 \\
\hline
\end{tabular}


Lead time yang dihasilkan pada kondisi saat ini untuk 1 batch produksi yaitu 5,039 hari, dengan adanya penetapan decoupling point, lead time yang dihasilkan yaitu 1,995 hari.

\section{Peramalan Permintaan}

Pola data yang terpilih berdasarkan hasil plotting data adalah pola data horizontal. Berdasrkan hasil uji kesalahan (error) menggunakan u-theil, metode peramalan yang terpilih berdasarkan nilai error terkecil adalah metode Single Moving Average. Gambar 3 merupakan hasil perhitungan peramalan metode Single Moving Average menggunakan win qsb.

\begin{tabular}{|c|c|c|c|c|c|c|c|c|c|}
\hline $\begin{array}{c}01-09-2022 \\
\text { Month }\end{array}$ & \begin{tabular}{|c|} 
Actual \\
Data \\
\end{tabular} & \begin{tabular}{|c|} 
Forecast by \\
2-MA
\end{tabular} & \begin{tabular}{|c|}
$\begin{array}{c}\text { Forecast } \\
\text { Error }\end{array}$ \\
\end{tabular} & CFE & MAD & MSE & MAPE [\%] & $\begin{array}{c}\text { Tracking } \\
\text { Signal } \\
\end{array}$ & R-square \\
\hline 1 & 1108 & & & & & & & & \\
\hline 2 & 1066 & & & & & & & & \\
\hline 3 & 1091 & 1087 & 4 & 4 & 4 & 16 & 0.3666361 & 1 & \\
\hline 4 & 1094 & 1078.5 & 15.5 & 19.5 & 9.75 & 128.125 & 0.8917276 & 2 & \\
\hline 5 & 1171 & 1092.5 & 78.5 & 98 & 32.66667 & 2139.5 & 2.829042 & 3 & 0.8025998 \\
\hline 6 & 1039 & 1132.5 & -93.5 & 4.5 & 47.875 & 3790.188 & 4.371541 & 9.399478E-02 & 0.1945564 \\
\hline 7 & 1189 & 1105 & 84 & 88.5 & 55.1 & 4443.35 & 4.910185 & 1.606171 & 0.2164665 \\
\hline 8 & 1119 & 1114 & 5 & 93.5 & 46.75 & 3706.958 & 4.166292 & 2 & 0.22132 \\
\hline 9 & 1284 & 1154 & 130 & 223.5 & 58.64286 & 5591.679 & 5.01748 & 3.811206 & 0.2914841 \\
\hline 10 & 1192 & 1201.5 & -9.5 & 214 & 52.5 & 4904 & 4.489917 & 4.07619 & 0.4215294 \\
\hline 11 & 1117 & 1238 & -121 & 93 & 60.11111 & 5985.889 & 5.194658 & 1.547135 & 0.5900676 \\
\hline 12 & 1204 & 1154.5 & 49.5 & 142.5 & 59.05 & 5632.325 & 5.086322 & 2.413209 & 0.5801617 \\
\hline 13 & & 1160.5 & & & & & & & \\
\hline 14 & & 1160.5 & & & & & & & \\
\hline 15 & & 1160.5 & & & & & & & \\
\hline 16 & & 1160.5 & & & & & & & \\
\hline 17 & & 1160.5 & & & & & & & \\
\hline 18 & & 1160.5 & & & & & & & \\
\hline 19 & & 1160.5 & & & & & & & \\
\hline 20 & & 1160.5 & & & & & & & \\
\hline 21 & & 1160.5 & & & & & & & \\
\hline 22 & & 1160.5 & & & & & & & \\
\hline 23 & & 1160.5 & & & & & & & \\
\hline 24 & & 1160.5 & & & & & & & \\
\hline
\end{tabular}

Gambar 3. Hasil Perhitungan Peramalan Metode Single Moving Average

\section{Pembuatan Jadwal Produksi Induk (JPI)}

Setelah mendapatkan nilai peramalan agregat 12 periode ke depan, selanjutnya yaitu menentukan nilai Jadwal Produksi Induk. Perhitungan Jadwal Produksi Induk dilakukan untuk mengetahui jumlah item yang akan diproduksi oleh perusahaan. Perhitungan yang dilakukan dimulai dari melakukan perhitungan kapasitas produksi untuk mengetahui kapasitas tersedia yang dimiliki oleh perusahaan hingga terakhir yaitu perhitungan disagregasi item untuk mendapatkan nilai JPI. Tabel 2 dan Tabel 3 merupakan rekapitulasi nilai JPI untuk seluruh produk akhir CV. X.

Tabel 2. Rekapitulasi Nilai JPI Kain Celup

\begin{tabular}{|c|c|c|c|c|c|c|c|c|c|c|c|c|c|}
\hline Periode & $\mathrm{Y}^{*}$ & $\mathbf{Y}$ & $\mathbf{E}$ & Ceruti & $\begin{array}{c}\text { Chiffon } \\
\text { Fine }\end{array}$ & $\begin{array}{l}\text { Diamond } \\
\text { IM }\end{array}$ & Moscrape & Balotelly & Saten & Amunzen & Hycon & $\begin{array}{c}\text { Woll } \\
\text { Peach }\end{array}$ & $\begin{array}{l}\text { Wolly } \\
\text { Crepe }\end{array}$ \\
\hline 13 & 996 & 1717 & 721 & 269 & 88 & 122 & 77 & 203 & 65 & 194 & 76 & 109 & 54 \\
\hline 14 & 996 & 1717 & 721 & 269 & 88 & 122 & 77 & 203 & 65 & 194 & 76 & 109 & 54 \\
\hline 15 & 996 & 1717 & 721 & 269 & 88 & 122 & 77 & 203 & 65 & 194 & 76 & 109 & 54 \\
\hline 16 & 996 & 1717 & 721 & 269 & 88 & 122 & 77 & 203 & 65 & 194 & 76 & 109 & 54 \\
\hline 17 & 996 & 1717 & 721 & 269 & 88 & 122 & 77 & 203 & 65 & 194 & 76 & 109 & 54 \\
\hline 18 & 996 & 1717 & 721 & 269 & 88 & 122 & 77 & 203 & 65 & 194 & 76 & 109 & 54 \\
\hline 19 & 996 & 1717 & 721 & 269 & 88 & 122 & 77 & 203 & 65 & 194 & 76 & 109 & 54 \\
\hline 20 & 996 & 1717 & 721 & 269 & 88 & 122 & 77 & 203 & 65 & 194 & 76 & 109 & 54 \\
\hline 21 & 996 & 1717 & 721 & 269 & 88 & 122 & 77 & 203 & 65 & 194 & 76 & 109 & 54 \\
\hline 22 & 996 & 1717 & 721 & 269 & 88 & 122 & 77 & 203 & 65 & 194 & 76 & 109 & 54 \\
\hline 23 & 996 & 1717 & 721 & 269 & 88 & 122 & 77 & 203 & 65 & 194 & 76 & 109 & 54 \\
\hline 24 & 996 & 1717 & 721 & 269 & 88 & 122 & 77 & 203 & 65 & 194 & 76 & 109 & 54 \\
\hline
\end{tabular}


Tabel 3. Rekapitulasi Nilai JPI Kain Printing

\begin{tabular}{|c|c|c|c|c|c|c|c|c|c|c|c|c|c|}
\hline Periode & $\mathbf{Y}^{*}$ & $\mathbf{Y}$ & $\mathbf{E}$ & Ceruti & $\begin{array}{c}\text { Chiffon } \\
\text { Fine }\end{array}$ & $\begin{array}{l}\text { Diamond } \\
\text { IM }\end{array}$ & Moscrape & Balotelly & Saten & Amunzen & Hycon & $\begin{array}{c}\text { Woll } \\
\text { Peach }\end{array}$ & $\begin{array}{l}\text { Wolly } \\
\text { Crepe }\end{array}$ \\
\hline 13 & 996 & 1130 & 134 & 218 & 71 & 99 & 62 & 164 & 52 & 157 & 61 & 88 & 44 \\
\hline 14 & 996 & 1130 & 134 & 218 & 71 & 99 & 62 & 164 & 52 & 157 & 61 & 88 & 44 \\
\hline 15 & 996 & 1130 & 134 & 218 & 71 & 99 & 62 & 164 & 52 & 157 & 61 & 88 & 44 \\
\hline 16 & 996 & 1130 & 134 & 218 & 71 & 99 & 62 & 164 & 52 & 157 & 61 & 88 & 44 \\
\hline 17 & 996 & 1130 & 134 & 218 & 71 & 99 & 62 & 164 & 52 & 157 & 61 & 88 & 44 \\
\hline 18 & 996 & 1130 & 134 & 218 & 71 & 99 & 62 & 164 & 52 & 157 & 61 & 88 & 44 \\
\hline 19 & 996 & 1130 & 134 & 218 & 71 & 99 & 62 & 164 & 52 & 157 & 61 & 88 & 44 \\
\hline 20 & 996 & 1130 & 134 & 218 & 71 & 99 & 62 & 164 & 52 & 157 & 61 & 88 & 44 \\
\hline 21 & 996 & 1130 & 134 & 218 & 71 & 99 & 62 & 164 & 52 & 157 & 61 & 88 & 44 \\
\hline 22 & 996 & 1130 & 134 & 218 & 71 & 99 & 62 & 164 & 52 & 157 & 61 & 88 & 44 \\
\hline 23 & 996 & 1130 & 134 & 218 & 71 & 99 & 62 & 164 & 52 & 157 & 61 & 88 & 44 \\
\hline 24 & 996 & 1130 & 134 & 218 & 71 & 99 & 62 & 164 & 52 & 157 & 61 & 88 & 44 \\
\hline
\end{tabular}

\section{Rough Cut Capacity Planning (RCCP).}

Perhitungan RCCP digunakan untuk menguji kelayakan dari nilai JPI. Perhitungan RCCP dilakukan dengan membandingkan kapasitas tersedia dengan kapasitas dibutuhkan dari jumlah JPI pada semua stasiun kerja pada setiap periodenya. RCCP digambarkan dalam grafik RCCP. Diketahui berdasarkan grafik yang digambarkan pada Gambar 4 bahwa kapasitas tersedia tidak dapat memenuhi kapasitas yang dibutuhkan sehingga perlu adanya penambahan kapasitas tersedia dengan melakukan subcontract.

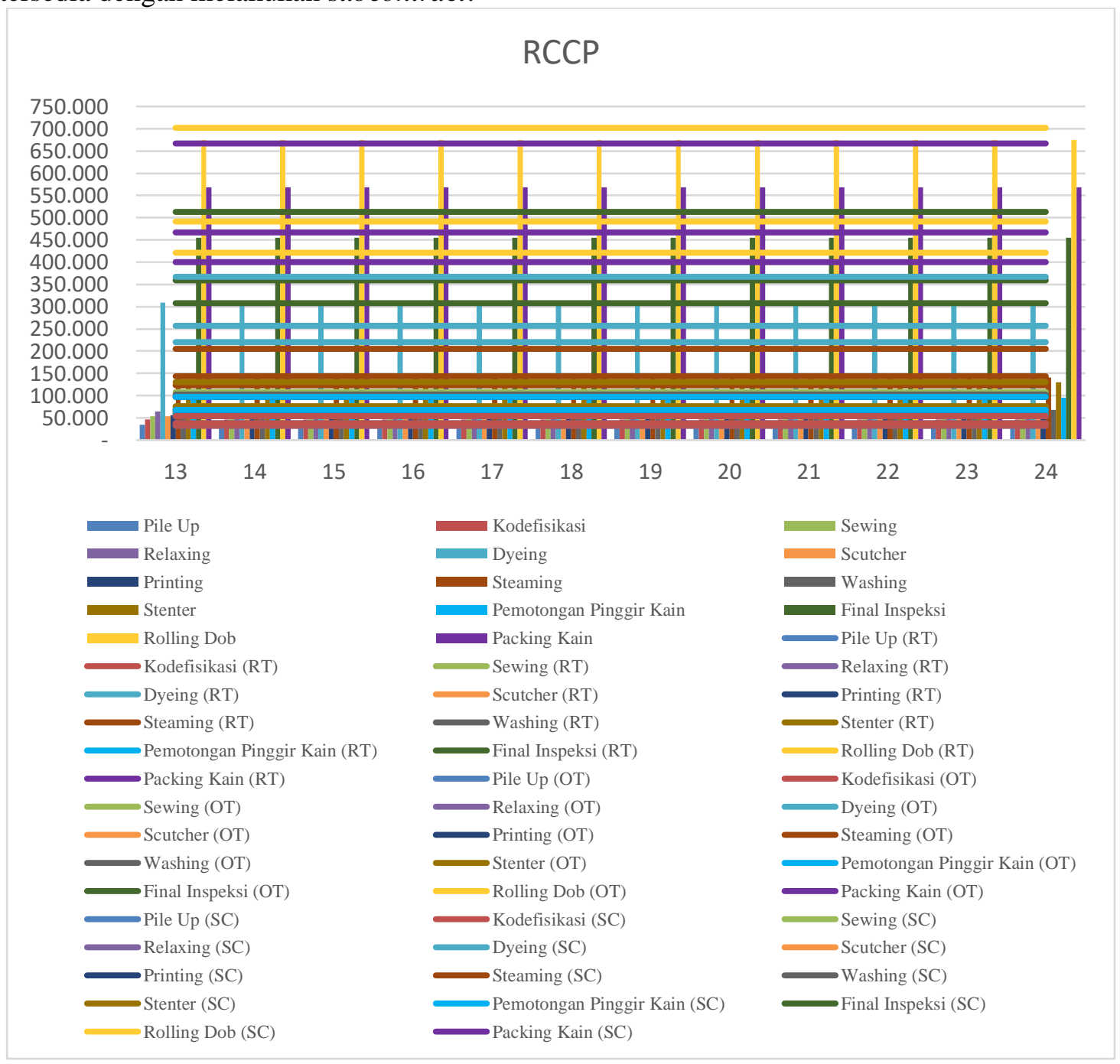

Gambar 4. Grafik RCCP 


\section{Material Requirements Planning (MRP)}

Perhitungan perencanaan kebutuhan material dilakukan dengan 4 tahapan yaitu, netting, Lotting, offsetting, dan exploding. Perhitungan MRP pada level 0 dilakukan untuk menghitung kebutuhan produksi dari masing-masing item produk yang dilakukan dengan menginput hasil JPI yang telah didapat sebagai GR. Hasil dari perhitungan JPI periode ke- 13 dibagi menjadi 24 karena dalam melakukan perhitungan MRP ini hanya dilakukan untuk 1 periode atau 1 bulan. Dalam 1 bulan, perusahaan memiliki waktu kerja sebanyak 24 hari sehingga MRP dilakukan untuk 24 hari kerja dalam sebulan. Tabel 5 merupakan perhitungan MRP level 4 untuk kain grey sewing, dimana GR yang digunakan berasal dari nilai penjumlahan POR level 3 item kain relaxing ceruti, kain relaxing chiffon fone, kain relaxing diamond IM, mosscrape, balotelly, saten, amunzen, hycon, woll peach, dan wolly crepe.

Tabel 5. MRP Level 4 Kain Grey Sewing

\begin{tabular}{|c|c|c|c|c|c|c|c|c|c|c|c|c|c|c|c|c|c|c|c|c|c|c|c|c|c|c|c|}
\hline \multirow[t]{2}{*}{ LS } & \multirow[t]{2}{*}{ LT } & \multirow[t]{2}{*}{$\mathrm{OH}$} & \multirow[t]{2}{*}{ SS } & \multirow{2}{*}{\multicolumn{2}{|c|}{ LV ITEM }} & \multirow[t]{2}{*}{ Ket $\quad$ PD } & \multicolumn{21}{|c|}{ HARI } \\
\hline & & & & & & & 1 & 2 & 3 & 4 & 5 & 6 & 7 & 8 & 9 & 10 & 11 & 12 & 13 & 14 & 15 & 16 & 17 & 18 & 19 & 20 & $\begin{array}{llll}21 & 22 & 23 & 24\end{array}$ \\
\hline \multirow[t]{6}{*}{$\mathrm{L} 4 \mathrm{~L}$} & \multirow[t]{6}{*}{1} & \multirow[t]{6}{*}{0} & \multirow{6}{*}{\multicolumn{2}{|c|}{0}} & \multirow{6}{*}{$\begin{array}{c}\text { Kain } \\
\text { Grey } \\
\text { Sewing }\end{array}$} & GR & 106 & 106 & 106 & 106 & 106 & 106 & 106 & 106 & 106 & 106 & 106 & 106 & 106 & 106 & 106 & 106 & 106 & 106 & 106 & 106 & 59 \\
\hline & & & & & & SR & 106 & & & & & & & & & & & & & & & & & & & & \\
\hline & & & & & & $\mathrm{POH}$ & 0 & 0 & 0 & 0 & 0 & 0 & 0 & 0 & 0 & 0 & 0 & 0 & 0 & 0 & 0 & 0 & 0 & 0 & 0 & 0 & 0 \\
\hline & & & & & & NR & 0 & 106 & 106 & 106 & 106 & 106 & 106 & 106 & 106 & 106 & 106 & 106 & 106 & 106 & 106 & 106 & 106 & 106 & 106 & 106 & 59 \\
\hline & & & & & & PORc & & 106 & 106 & 106 & 106 & 106 & 106 & 106 & 106 & 106 & 106 & 106 & 106 & 106 & 106 & 106 & 106 & 106 & 106 & 106 & 59 \\
\hline & & & & & & POR & 106 & 106 & 106 & 106 & 106 & 106 & 106 & 106 & 106 & 106 & 106 & 106 & 106 & 106 & 106 & 106 & 106 & 106 & 106 & 59 & \\
\hline
\end{tabular}

Berdasarkan hasil perhitungan MRP untuk kain grey sewing, dapat dilihat nilai POR untuk item kain grey sewing pada setiap periodenya membuatuhkan 106 batch/hari. hal tersebut menunjukkan bahwa perusahaan harus melakukan pemesanan 1 hari sebelum item tersebut dibutuhkan. Persediaan kain grey sewing ini juga harus memerhatikan kapasitas yang dimiliki oleh perusahaan. Berdasarkan hasil perhitungan kapasitas tersedia yang memproduksi kain grey sewing didapat kapasitas per hari nya adalah 155,681. Oleh karena itu, maka dapat disimpulkan bahwa kapasitas tersedia sk sewing dapat memenuhi kebutuhan perusahaan untuk memproduksi kain grey sewing yang dijadikan decoupling point.

\section{Kesimpulan}

Berdasarkan pembahasan dalam penelitian ini, peneliti menyimpulkan beberapa hasil penelitian sebagai berikut:

1. Saat ini CV. X (CV. X) mengalami permasalahan pada ketersediaan bahan baku utama (kain grey) terkait dengan tidak tersedianya bahan baku kain grey saat dibutuhkan. Permasalahan tersebut terjadi karena keterlambatan bahan baku. Keterlambatan kedatangan bahan baku menyebabkan keterlambatan penyelesaian produk.

2. Penetapan decoupling point dilakukan untuk menentukan batas dimana persediaan dapat disimpan agar dapat memperpendek jarak antara order dengan delivery atau customer lead time. Penetapan decoupling point pada proses pembuatan kain celup maupun printing di CV. X terletak diproses sewing. Nilai leadtime di CV. X sebelum dilakukan penetapan decoupling point yaitu 6 hari untuk 1 batch produksi, dan setelah dilakukan penetapan decoupling point nilai leadtime berkurang menjadi 2 hari untuk 1 batch produksi. Perbedaan antara sebelum dan sesudah dilakukan penetapan decoupling point yaitu 4 hari.

3. Perencanaan produksi yang diusulkan yaitu dengan melakukan peramalan permintaan, perencanaan agregat, disagregasi, RCCP, dilanjutkan dengan melakukan perencanaan kebutuhan material menggunakan material requirement planning (MRP) khusus untuk kain grey sewing. Hasil yang didapat dari perhitungan MRP adalah mengetahui kapan material dipesan dan diterima agar persediaan tersebut dapat menjamin produksi berjalan lancar untuk memenuhi customer lead time. 


\section{Acknowledge}

Peneliti mengucapkan terimakasih kepada kedua orang tua yang telah memberikan dukungan, kedua pembimbing yaitu Bapak Ir. Chaznin R. Muhammad, S.T., M.T. dan Ibu Dr. Nita P. A, Hidayat, Ir., M.T. yang telah memberikan ilmu, arahan, dan bimbingannya dalam penelitian ini. Peneliti juga mengucapkan terima kasih kepada semua pihak yang sudah memberikan dukungan, ilmu, dan doa dalam penyusunan penelitian ini, sehingga penelitian ini dapat diselesaikan dengan baik.

\section{Daftar Pustaka}

[1] Kotayet, W., Eltawil, A. B., dan Fors, M. N., 2011. A Hierarchical Production Planning Framework For The Textile Indsutry With Make to Order and Make to Stock Considerations, $22^{\text {nd }}$ International Conference on Computer Aided Production Engineering, [Online].

[2] Van Donk, D. P., 2001. Make to Stock or Make to Order The Decoupling Point in The Food Processing Industries. Gronongen: Faculty of Management and Organization, University of Groningen. Interntional Journal of Production Economics. Tersedia online pada www.elsevier.com/locate/dsw.

[3] Ulfah, H.S., Prasetyaningsih, E., dan Amaranti, R., 2016. Perencanaan Produksi Hirarkis Multi Produk Untuk Industri Farmasi Dengan Pendekatan Kombinasi Strategi Make To Stock dan Make To Order, [Online] Tersedia pada: < https://docplayer.info/44142260Prosiding-teknik-industri-issn.html > [Diakses 28 November 2020].

[4] Olhager, J., 2010. The role of the customer order decoupling point in production and supply chain management. Computer in Industry, [e-journal], 61(9), 863-868 Tersedia pada: <https://doi.org/10.1016/j.compind.2010.07.011 > [Diakses 10 November 2020].

[5] Olhager, J., 2012. The role of decoupling points in value chain management. Modelling Value Selected Papers of The $1^{\text {st }}$ International Conference on Value Chain Management, [Online] Tersedia pada: <https://www.semanticscholar.org/paper/The-Role-of-DecouplingPoints-in-Value-Chain-Olhager/d5fb1840582f340bf6e499af0547f2d5d75111be> [Diakses 10 November 2020]

[6] Makridakis, S., Wheelwright, S.C., dan Mcgee, V.E., 1999. Metode dan Aplikasi Peramalan. Jakarta: Erlangga.

[7] Munson, C., Heizer, J., dan Render, B., 2017. Operations Management: Sustainability and Supply Chain Management. Twelfth Edition. Washington: Pearson Education, Inc

[8] Bedworth, D. D., dan Bailey, J. E., 1987. Integrated Production Control Sistem. Jhon Wiley \& Sons.

[9] Fogarty, D.W., Blackstone, J.H., dan Hoffman, T.R., 1991. Production and Inventory Management. South-Western Publishing Co.

[10] Oden, H.W., 1993. Handbook of Material \& Capacity Requirement Planning. McGrow-Hill. 